\title{
TOWARD SERS-BASED DYNAMIC DETECTION OF INSULIN DIFFUSING THROUGH HYDROGEL MATRICES
}

\author{
${ }^{1}$ Farnoush SALEHTASH, ${ }^{1,2}$ Adriana ANNUŠOVÁ, ${ }^{1}$ Vojtech NÁDAŽDY, ${ }^{1}$ Yuriy HALAHOVETS, \\ ${ }^{3}$ Paweł ALBRYCHT, ${ }^{1,2}$ Peter ŠIFFALOVIČ, ${ }^{1,2}$ Matej JERGEL, ${ }^{1,2}$ Eva MAJKOVÁ, \\ ${ }^{4}$ Zuzana KRONEKOVÁ, ${ }^{4}$ Michal PELACH, ${ }^{2,4}$ Igor LACÍK \\ ${ }^{1}$ Institute of Physics, Slovak Academy of Sciences, Bratislava, Slovakia, EU, farnoush.salehtash@savba.sk \\ ${ }^{2}$ Centre for Advanced Materials Application, Slovak Academy of Sciences, Bratislava, Slovakia, EU, \\ eva.majkova@savba.sk \\ 3Institute of Physical Chemistry, Polish Academy of Sciences, Warsaw, Poland, EU, palbrycht@ichf.edu.pl \\ ${ }^{4}$ Polymer Institute, Slovak Academy of Sciences, Bratislava, Slovakia, EU, igor.lacik@savba.sk
}

https://doi.org/10.37904/nanocon.2021.4363

\begin{abstract}
Insulin is a peptide hormone produced by beta cells of pancreatic islets. In type 1 diabetes mellitus, these islets are destroyed by the body's own immune system, no insulin is produced and the blood glucose level is increased. Nowadays, efforts in combatting type 1 diabetes focus on the transplantation of islets immunoprotected in microspheres made of non-covalently crosslinked hydrogels. The functionality of the encapsulated islets is retained, while the hydrogel matrix allows permeation of the produced insulin into the bloodstream. The applicability of these microspheres has been extensively studied in vivo. However, prior to biological models, a dynamic detection method to monitor the production of insulin and its diffusion through the microspheres is still missing. Herein, we apply the Surface Enhanced Raman Scattering (SERS) technique to detect physiologically relevant concentrations of insulin using planar Ag SERS substrates, while considering their implementation for monitoring insulin diffusion through alginate matrices. Insulin was detected after drying SERS planar substrates in a concentration range of $10^{-3}-10^{-12} \mathrm{M}$. Additionally, we demonstrated the decrease in the deposition time using an alternating electric field. Moreover, the in situ monitoring of the SERS signal from insulin molecules has certain limitations when conducting experiments for SERS substrates submerged in water. As the secretion of insulin and its diffusion across the immunoprotective microspheres is a dynamic process, the development of an adequate detection method is expected to lead to a better understanding of these processes as a function of time, matrix composition, and glucose intake.
\end{abstract}

Keywords: Insulin, alginate-based hydrogel matrices, Surface Enhanced Raman Scattering

\section{INTRODUCTION}

One of the most sensitive and powerful bioanalytical techniques used in a wide range of applications is Surface Enhanced Raman Scattering (SERS). It is particularly useful for the sensing of bioactive molecules [1,2], i.e. compounds that have biological effects on the human body. The development of quick and reliable techniques for in situ detection of bioactive molecules is important in biomedical research and drug discovery.

In SERS, the otherwise relatively weak Raman signals of a target molecule are amplified by several orders of magnitude when trapped between the nanogaps of a noble metal nanostructure surface (e.g. Au or Ag) [3]. The signal enhancement is attributed to different effects. The largest amplification comes from the electromagnetic near fields. The charge transfer processes or chemical enhancement happens due to the chemical adsorption of molecules to SERS surfaces [4,5]. SERS is one of the most valuable methods for ultrahigh-resolution detection and analysis of bioactive compounds $[5,6]$. 
Insulin is necessary to maintain the physiological carbohydrate, protein, and fat metabolisms and plays a crucial role in controlling many diseases that can affect human health. Insulin is a peptide hormone synthetized by the beta cells of the pancreatic islets [7]. It consists of two peptide chains, A with 21 amino acid residues and B with 30 residues, linked by two disulfide connecting cysteine A7 and B7 and residues A20 and B19 [8]. The disruption of insulin secretion by the beta cells leads to diabetes mellitus [9]. Type 1 diabetes mellitus is an autoimmune deficiency that arises when the beta cells are destroyed by the body's own immune system. Low levels of insulin increase blood glucose and cause hyperglycemia. Patients then depend on exogenous insulin for survival, and there is currently no cure. One method currently under research and development involves the encapsulation of beta cells in a protective coating that is biocompatible and semipermeable, but does not induce an immune response upon their transplantation. Thus, insulin secreting cells could function properly and no exogenous insulin administration would be required. The most commonly employed are noncovalently crosslinked alginate hydrogels as they provide favorable physiological conditions for islets during the encapsulation processes [10].

Several studies described the detection of low insulin concentrations at quantities that can satisfy the requirements for monitoring of insulin levels in the human body. Hassanian et al. [1] realized SERS detection of reduced human insulin, where the disulfide bonds are broken. This allows the insulin molecules to chemically adsorb onto the SERS substrates. Thus, Au-S bonds are formed, allowing both electromagnetic and chemical enhancements to arise. They measured nine different concentrations of the protein, from $10 \mathrm{fM}$ to $300 \mathrm{pM}$. Another study by Cho et al. [11] presented a columnar 3D Au SERS substrate with a dynamic range from $100 \mathrm{pM}$ to $50 \mathrm{nM}$ and detection limit $35 \mathrm{pM}$. Insulin concentrations in pancreatic islet secretions were characterized under low and high glucose conditions with high spatial uniformity of the Raman signal. The peak at $1002 \mathrm{~cm}^{-1}$, corresponding to the ring-breathing mode of aromatic phenylalanine, was used to monitor the insulin signal. Gholami et al. reported a novel SERS quenching method for the detection of proteins and biomolecules [12,13]. They used Au nanoparticles functionalized by benzothiazole azo dye. The latter is displaced from the SERS substrates surface after its interaction with biomolecules with reduced disulfide bonds. This Raman probe was used to quantify insulin in the concentration range of $10^{-8}-10^{-14} \mathrm{M}$.

Although a lot of research has focused on low level insulin detection using SERS, there is still a need for the development of dynamic detection methods. Precise quantification of insulin secreted by beta cells is of primary importance in determining the degree of functionality of polymeric matrices employed in encapsulation procedures. The above-mentioned works studied the signal of insulin in a dried, presumably crystalline state. However, the hydrogel microcapsules are prone to instantaneous dehydration in non-aqueous environment, which makes the in situ insulin permeation monitoring more difficult. Our previous study successfully reported the application of label-free Confocal Raman Microscopy (CRM) to monitor structural changes in the hydrogel matrices of alginate-based microspheres [14]. The present work investigates the possibility of monitoring the diffusion process of insulin molecules through alginate-based hydrogel matrices using planar SERS substrates and under water immersion. First, the limits of detection for insulin molecules in our diagnostic system are presented. Second, we demonstrate the successful acceleration of the deposition time of insulin under the influence of an alternating electric field. Finally, the insulin SERS signal is monitored from the SERS substrate in the aqueous conditions.

\section{EXPERIMENTAL PART}

\subsection{Instrumentation}

All SERS experiments were carried out at a controlled room temperature of $20^{\circ} \mathrm{C}$, using a WITec alpha $300 \mathrm{R}+$ confocal Raman microscope equipped with a WITec UHTS300 spectrometer (1200 lines/mm grating) coupled to an EMCCD camera. The $785 \mathrm{~nm}$ laser line with the power of 5 and $30 \mathrm{~mW}$ was employed to excite the Raman signal. A water immersion objective (Carl Zeiss $20 \times / 1 \mathrm{NA}$ ) and a $100 \mu \mathrm{m}$ diameter optical fiber were 
used to collect the spectra. We performed single-spot acquisitions with integration times (IT) of 10 or $20 \mathrm{~s}$ and accumulation number of 1 or 5 , respectively (longer IT were used for measurements performed on SERS substrates immersed in water). Additional raster scanning images were done to monitor the spatial homogeneity of the insulin signal $(50 \times 50 \mu \mathrm{m}, 100 \times 100$ lines, IT 1s).

\subsection{SERS substrates}

We used planar SERS substrates provided by SERSitive (Institute of Physical Chemistry, Polish Academy of Sciences, Warsaw), manufactured using electrodeposition of silver nanoparticles on an Indium-tin oxide (ITO) glass surface. The Ag hydrophilic substrates had an active area of $5 \times 4 \mathrm{~mm}$ (Premium-Silver SERS) and $3.5 \times 3.5 \mathrm{~mm}$ (S-Silver SERS). Figure 1 presents photos of the substrates, and also the SEM and AFM images of the deposited $\mathrm{Ag}$ on the surface. These SERS substrates are capable of amplifying the normal Raman signals of about $100 \mathrm{M}$ times.
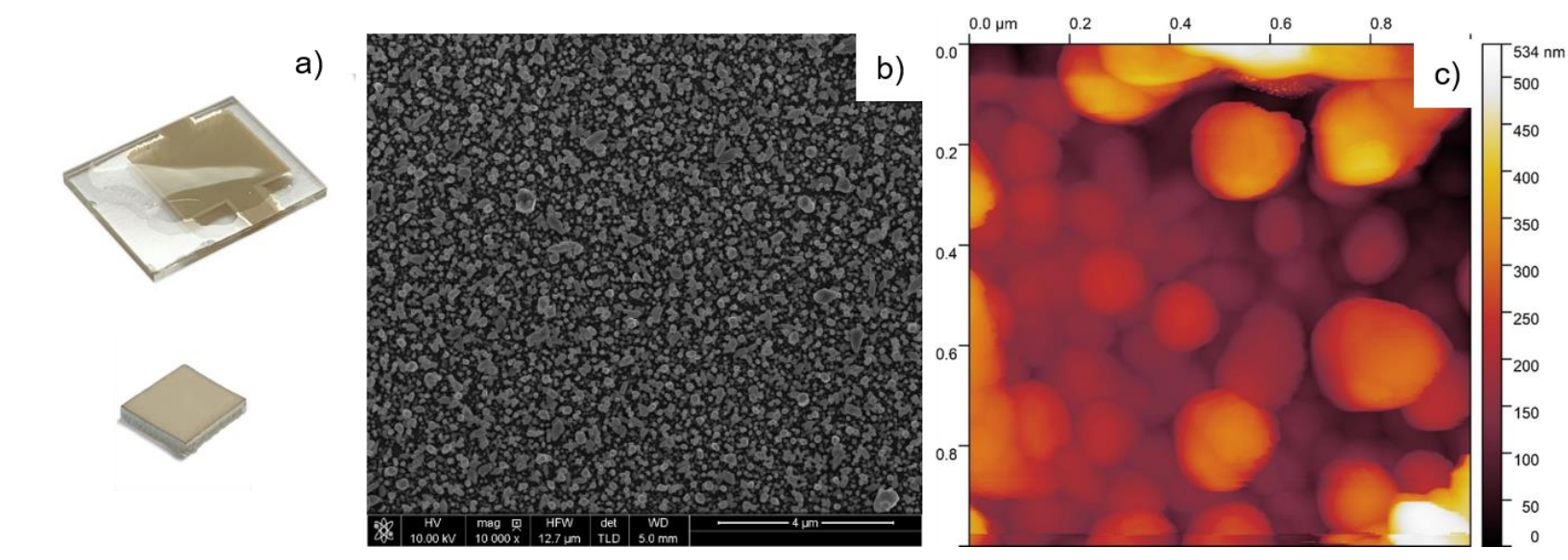

Figure 1 Optical image of the SERSitive substrates: Premium-Silver and S-Silver (a) [15, 16], SEM (b) [17] and, AFM (c) image of Ag nanoparticles electrodeposited on the surface of the ITO glass

\subsection{Deposition of insulin on planar substrates}

A human insulin (Sigma-Aldrich) solution $\left(1.7 \times 10^{-3} \mathrm{M}\right.$ ) was used to prepare a series of different concentrations of insulin solutions in the concentration range of $10^{-3}-10^{-12} \mathrm{M}$ by dilution in filtered deionized water $(\mathrm{pH}$ of 7.5). In this step, the smaller substrates (S-Silver SERS) were immersed in $200 \mu \mathrm{l}$ of the indicated concentrations in an Eppendorf tube for $24 \mathrm{~h}$, followed by drying the substrates in air, without a rinsing step.

To investigate the influence of electrical field on the time of insulin deposition on the substrates surface, we followed the work of Richter et al. [18]. The larger Premium-Silver SERS substrate served as one of the electrodes in a cell, realized according to [18] using a 3D printer. On the counter electrode (ITO substrate without Ag nanoparticles), a glass-PTFE foil of $250 \mu \mathrm{m}$ thickness was placed to avoid Faraday currents flow. A volume of $50 \mu \mathrm{l}$ of $1 \mathrm{mM}$ insulin solution was pipetted into the cell. An alternating electrical field of $+10 \mathrm{~V}$ (square waveform with oscillations from 0 to $+10 \mathrm{~V}$ ) and $1 \mathrm{kHz}$ was applied on the electrodes for 5 min (Keithley 3390 waveform generator, Tektronix 2236 A oscilloscope). The chosen polarity and frequency were determined based on Zeta potential measurements (Malvern Zetasizer Nano ZS90) of $1 \mathrm{mM}$ insulin solution [18]. The Zeta potential and the electrophoretic mobility are equal to $-26.6 \mathrm{mV}$ and $2.084 \mu \mathrm{m} . \mathrm{cm} / \mathrm{Vs}$, respectively. After deposition, no rinsing step was applied, and the substrates were dried in air. In some experiments, the substrates were then immersed under water during Raman measurements. Afterwards a second drying step followed, without excessive rinsing of the substrates. 


\section{RESULTS AND DISCUSSION}

\subsection{Low concentration insulin detection using planar SERS substrates}

Figure 2a shows spectra obtained from different spots of four different S-Silver substrates previously immersed in $\mathrm{mM}, \mu \mathrm{M}, \mathrm{nM}$, and $\mathrm{pM}$ insulin solutions. We were able to detect insulin in the nM-pM range, which corresponds to the insulin levels in human blood. The most pronounced peaks were identified as vibrational modes of phenylalanine (Phe) and tyrosine (Tyr) molecules [19]. It should be noted that no Raman peak of insulin was observed from substrates not containing Ag nanoparticles after immersion in $1 \mathrm{mM}$ insulin solution.

a)

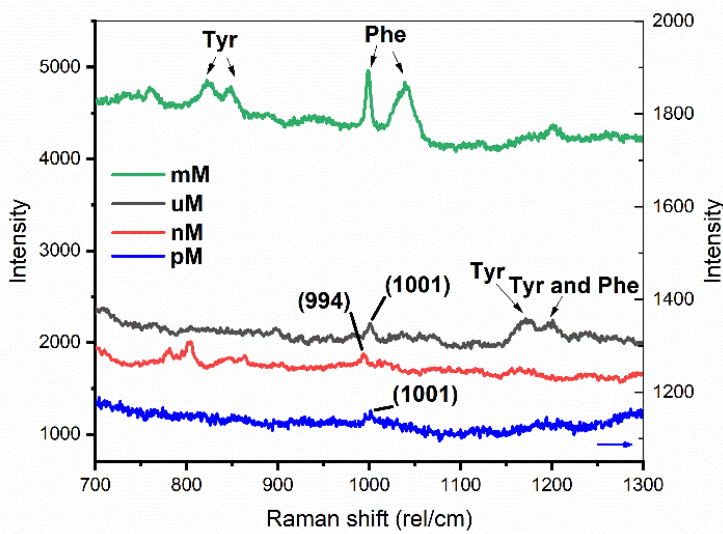

b)

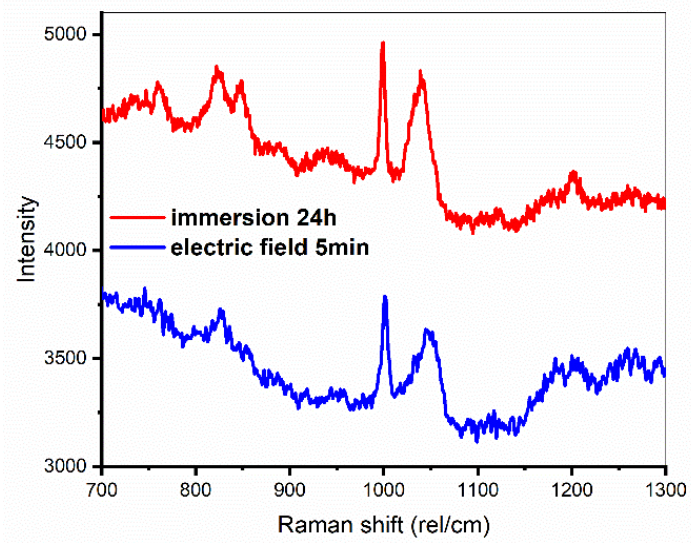

Figure 2 A comparison between SERS spectra of different concentrations of insulin solution (mM, $\mu \mathrm{M}, \mathrm{nM}$, and $\mathrm{pM}$ ) from substrates prepared by the immersion deposition method (a) and a comparison of a SERS spectrum of $1 \mathrm{mM}$ insulin solution deposited on the substrate using an alternating electric field to the $24 \mathrm{~h}$ immersion deposition method (b).

\subsection{Insulin deposition on SERS substrates using an alternating electric field}

In the work of Richter et al. [18], a shortening of deposition time was reported for different proteins and small molecules after applying an alternating electric field with a polarity depending on the charge of the analyte. Our results confirm that this method is also applicable in the case of $1 \mathrm{mM}$ human insulin solution. The recorded spectra after only 5 min of electric field application resulted in homogenous and comparable signals to those obtained from substrates immersed in the same insulin concentration solution for $24 \mathrm{~h}$ (Figure 2b). The spatial uniformity of the absorbed molecules was also confirmed by the substrates raster images (not included here).

\subsection{SERS signal of insulin from substrate immersed in water}

Figure 3a depicts the spectrum measured from a dried substrate prepared under the influence of an electric field. As mentioned in the previous section, highly uniform and pronounced insulin peaks were detected on the surface. After these measurements, the substrate was immersed in $1.5 \mathrm{ml}$ of deionized water $(\mathrm{pH}=7.5)$ in a plastic Petri dish. The substrate was scanned again using the same acquisition parameters as for dried substrate. However, no insulin signal was detected using these conditions. Insulin peaks, uniformly distributed on the surface, appeared only after increasing the power from 5 to $30 \mathrm{~mW}$. However, their intensity decreased significantly compared to the signal from the dried substrate. This behavior was reproducible. As insulin is present in water in a dissolved form, the functional groups are charged depending on the $\mathrm{pH}$. This in turn affects their ability to remain bonded with the substrate and influences the signal enhancement. The change in signal intensity compared to the signal from the crystalline insulin is rather significant. The intensity is comparable to a signal from a dried substrate previously immersed in $\mathrm{pM}$ concentration solution (see Figure 2a). This puts limitations on in situ dynamic detection of insulin in water. Figure $3 \mathrm{~b}$ shows the 
comparison of spectra from substrates dried before and after the immersion test (i.e. dried substrate after deposition of insulin using electric field and substrate after the second drying step, respectively). Insulin did not dissolve from the substrate completely into water but remained on the SERS substrate surface, as pronounced insulin peaks are again visible. By raster imaging, we confirmed that insulin is still homogeneously distributed on the surface. However, there is a difference in the excitation of the phenylalanine vibrational modes, manifested by a change in the intensity ratios between 1001 and $1035 \mathrm{rel}^{\mathrm{cm}} \mathrm{cm}^{-1}$. Further study will involve lower concentration insulin solutions and $\mathrm{pH}$ dependent measurements, as well as the adaptation of this method for in situ detection of insulin diffusing through hydrogel matrices.

a)

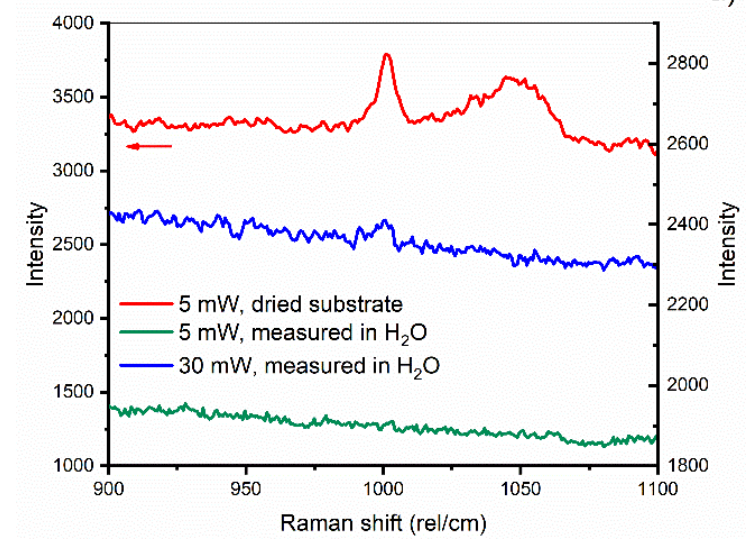

b)

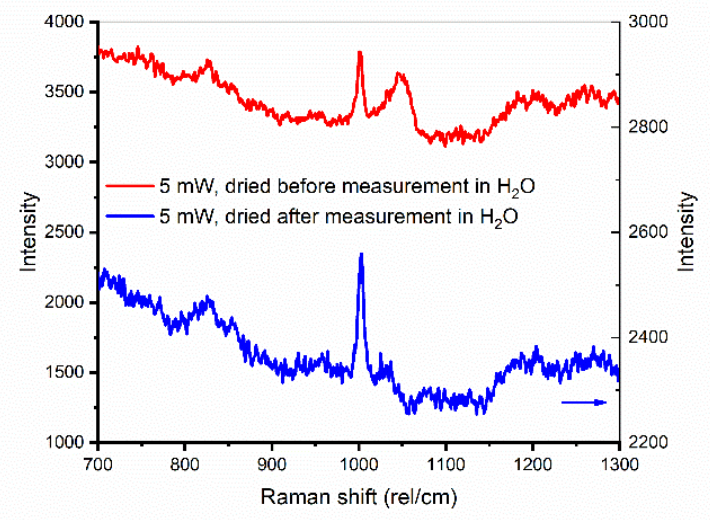

Figure 3 Comparison of spectra from substrates prepared using an alternating electric field, measured under different conditions (a) and comparison of spectra from substrates dried before and after the immersion test (b).

\section{CONCLUSION}

We studied the possibilities of detecting SERS signal for human insulin from planar Ag SERS substrates, dried as well as immersed in water. In the next step, this method will be applied for in situ dynamic monitoring of insulin diffusing through alginate-based hydrogel matrices. A detection limit of around $\mathrm{nM}$ to $\mathrm{pM}$ concentrations was achieved for a dried substrate. However, certain limitations were encountered in the detection of insulin SERS signal for a substrate immersed in water.

\section{ACKNOWLEDGEMENTS}

Financial support of the projects APVV-14-0120 and APVV-18-0480 is acknowledged. This work was performed during the implementation of the project Building-up Centre for advanced materials application of the Slovak Academy of Sciences, ITMS project code 313021 T081 supported by the Integrated Infrastructure Operational Programme funded by the ERDF. We would like to express our appreciation to professor Marek Procházka (Institute of Physics of Charles University in Prague) for helpful discussions.

\section{REFERENCES}

[1] W. A. HASSANAIN and E. L. IZAKE, "Toward Label-Free SERS Detection of Proteins through Their Disulfide Bond Structure." SLAS Discov. [online]. 2020, vol. 25, no. 1, pp. 87-94, 2020. Available from: https://doi.org/10.1177/2472555219875102.

[2] D. CIALLA et al. "Surface-enhanced Raman spectroscopy (SERS): Progress and trends." Anal. Bioanal. Chem. [online]. 2012, vol. 403, no. 1, pp. 27-54. Available from: https://doi.org/10.1007/s00216-011-5631-x. 
[3] S. Y. DING, E. M. YOU, Z. Q. TIAN, and M. MOSKOVITS. "Electromagnetic theories of surface-enhanced Raman spectroscopy." Chemical Society Reviews. [online]. 2017, vol. 46, no. 13. Royal Society of Chemistry, pp. 40424076. Available from: https://doi.org/10.1039/c7cs00238f.

[4] M. ŠUBR, A. KUZMINOVA, O. KYLIÁN, and M. PROCHÁZKA, "Surface-enhanced Raman scattering (SERS) of riboflavin on nanostructured Ag surfaces: The role of excitation wavelength, plasmon resonance and molecular resonance." Spectrochim. Acta - Part A Mol. Biomol. Spectrosc. [online]. 2018, vol. 197, pp. 202-207. Available from: https://doi.org/10.1016/j.saa.2018.01.055.

[5] M. F. MROZEK, D. ZHANG, and D. BEN-AMOTZ, "Oligosaccharide identification and mixture quantification using Raman spectroscopy and chemometric analysis." Carbohydr. Res. [online]. 2004, vol. 339, no. 1, pp. 141-145. Available from: https://doi.org/10.1016/i.carres.2003.09.019.

[6] B. SHARMA, R. R. FRONTIERA, A. I. HENRY, E. RINGE, and R. P. VAN DUYNE, "SERS: Materials, applications, and the future." Mater. Today. [online]. 2012, vol. 15, no. 1-2, pp. 16-25. Available from: https://doi.org/10.1016/S1369-7021(12)70017-2.

[7] C. ORTIZ, D. ZHANG, Y. XIE, V. J. DAVISSON, and D. BEN-AMOTZ. "Identification of insulin variants using Raman spectroscopy." Anal. Biochem. [online]. 2004, vol. 332, no. 2, pp. 245-252. Available from: https://doi.org/10.1016/j.ab.2004.06.013.

[8] J. BRANGE and L. LANGKJOER. "Insulin structure and stability." Pharm. Biotechnol. [online]. 1993, vol. 5, no. 1922, pp. 315-350. Available from: https://doi.org/10.1007/978-1-4899-1236-7 11.

[9] P. RORSMAN and M. BRAUN. "Regulation of insulin secretion in human pancreatic islets." Annu. Rev. Physiol. [online]. 2013, vol. 75, pp. 155-179. Available from: https://doi.org/10.1146/annurev-physiol-030212-183754.

[10] T. ANDERSEN, P. AUK-EMBLEM, and M. DORNISH, "3D Cell Culture in Alginate Hydrogels." Microarrays. [online]. 2015, vol. 4, no. 2, pp. 133-161. Available from: https://doi.org/10.3390/microarrays4020133.

[11] H. CHO et al., "Surface-Enhanced Raman Spectroscopy-Based Label-Free Insulin Detection at Physiological Concentrations for Analysis of Islet Performance." ACS Sensors. [online]. 2018, vol. 3, no. 1, pp. 65-71. Available from: https://doi.org/10.1021/acssensors.7b00864.

[12] M. D. GHOLAMI, P. SONAR, G. A. AYOKO, and E. L. IZAKE. "A highly sensitive SERS quenching nanosensor for the determination of tumor necrosis factor alpha in blood." Sensors Actuators, B Chem. [online]. 2020, vol. 310, p. 127867. Available from: https://doi.org/10.1016/j.snb.2020.127867.

[13] M. D. GHOLAMI, P. SONAR, G. A. AYOKO, and E. L. IZAKE. "A SERS quenching method for the sensitive determination of insulin." Drug Test. Anal. [online]. 2021, vol. 13, no. 5, pp. 1048-1053. Available from: https://doi.org/10.1002/dta.2808.

[14] Z. KRONEKOVÁ et al. "Structural changes in alginate-based microspheres exposed to in vivo environment as revealed by confocal Raman microscopy." Sci. Rep. [online]. 2018, vol. 8, no. 1, pp. 1-12. Available from: https://doi.org/10.1038/s41598-018-20022-y.

[15] "SERSitive hydrophilic Premium-Silver SERS substrate. [online]." Available from: https://sersitive.eu/shop/silver$\underline{\mathrm{m} /}$ (accessed Oct. 18, 2021).

[16] "SERSitive hydrophilic S-Silver SERS substrate. [online]. " https://sersitive.eu/shop/silver-s/ (accessed Oct. 18, 2021).

[17] "SEM image of S-Silver SERS substrate. [online]. " Available from: https://sersitive.eu/shop/silver-s/ (accessed Oct. 18, 2021).

[18] Ł. RICHTER et al., "Fast and efficient deposition of broad range of analytes on substrates for surface enhanced Raman spectroscopy." Biosens. Bioelectron. [online]. 2020, vol. 156. Available from: https://doi.org/10.1016/j.bios.2020.112124.

[19] S. MANGIALARDO, F. PICCIRILLI, A. PERUCCHI, P. DORE, and P. POSTORINO. "Raman analysis of insulin denaturation induced by high-pressure and thermal treatments." J. Raman Spectrosc. [online]. 2012, vol. 43, no. 6, pp. 692-700. Available from: https://doi.org/10.1002/jrs.3097. 